\title{
Eco-friendly approach to electro-mobility (Avangard approach)
}

\author{
Marcin Mirosław ${ }^{1 *}$ Tomasz Mirosław ${ }^{1}$ Jakub Deda², Adam Zawadzki², \\ ${ }^{1}$ Polevs sp. z o. o Poland \\ ${ }^{2}$ Institute of Vehicles and Construction Machinery Engineering, Faculty of Automotive and \\ Construction Machinery Engineering, Warsaw University of Technology
}

\begin{abstract}
Electric vehicles are offered by many car companies. They are considered ecological, although in terms of power it depends on the energy system, in particular a source of power to charge cars. In case of the production version, and operation may be less or more for a wide meaning of environment. In the article, the authors will present the issues of ecological use of electric vehicles, comparing the combustion and electric environmental studies. An analysis of the common electric vehicle structures and their operation will be presented, in which the environmental performance of vehicles and their positive impact on the quality of life can be achieved or enhanced by a new approach to the design, production and servicing method [1-4]. Authors of final output products of production based on the concept of industry 4.0+ [5], where the final products are supplied by SMEs (Small and Medium Enterprises). The authors mention the business model [6] that stimulates the development of SME sales and the sharing of knowledge. In the described model of vehicle production, which can be extended to the manufacturing of small agricultural and municipal machines, new methods of design (using artificial intelligence) and production, including $3 \mathrm{D}$ printing and others, play an important role. The authors will present several technologies used in small-lot production and a forecast of their use.
\end{abstract}

\section{Introduction}

Emissions of greenhouse gases and exhaust fumes containing particulates that pollute the air and cause disease are just two of the many charges against internal combustion cars. Transportation of people and goods is a very important area of human life on which many others depend [1-3].

An alternative solution is to replace combustion vehicles with electric or natural gas. However, when considering the environmental impact of introducing electric cars, one can doubt whether this is true if the entire life cycle of a vehicle is followed [4-6].

\footnotetext{
*Corresponding author: marcin.miroslaw@polevs.pl
} 
The total carbon footprint of a gasoline, diesel or electric car can be similar if we adopt the traditional model of production, operation and disposal. [7]

Electric vehicles' carbon footprint is influenced by the way they operate and the way electricity is generated. In Poland, the problem of energy is more complicated than in other European countries. The vast majority of electricity in Poland comes from coal-fired or lignite-fired power plants. The efficiency of thermal power plants is about $40 \%$. Modern filters placed on electro-coal-fired chimneys reduce the amount of solid particles emitted, and waste heat is used to heat apartments or production plants, e.g. greenhouses.

There are also some costs associated with energy transmission to vehicles: adapting the power grid, taking the vehicle out of service for a charging time that is still taking too long and there are still too few charging stations. An additional problem that is expected in the near future is the environmental impact of the battery disposal process.

Another problem of northern countries is low operating temperatures, in which the battery efficiency drops significantly. Use in low temperatures requires heating the cabin, which puts an additional burden on the batteries, and unaccustomed to the high temperatures that are more and more frequent in Poland in summer, Polish residents are eager to use air conditioning. The total efficiency of electric vehicles in Poland powered by coal-fired power plants is over $40 \%$.

In normal operation, the battery charge decreases with the number of kilometres travelled, thus the efficiency of the battery decreases, and an increase in the temperature of the windings and magnets also reduces the efficiency of the system. This means that electric vehicles are more efficient over short distances than over longer distances. Drive between garages or charging points, in which the vehicle is conditioned: heated or cooled, it does not require switching on the heating and cooling systems, and thus reduces energy consumption.

Cars powered by modern diesel engines are equipped with catalytic converters and filters for particulate matter and NOx utilizing, and their efficiency is above 40\% (and manufacturers' announcements indicate the efficiency of new engines at 50\%]) may not be less environmentally friendly than electric cars, whose primary energy comes from coal-fired power plants. Modern combustion cars have exhaust gas purity standards, and the excess heat is used to heat the passenger compartment. The power needed for air conditioning, just like in electric cars, increases the demand for energy (fuel consumption). Such arguments, especially in countries where electricity is produced from coal, do not make sense. In many countries, work is underway on synthetic fuel, of vegetable origin, which is not only to prevent an energy crisis caused by the consumption of resources, but also the creation of a closed $\mathrm{CO}_{2}$ cycle.

However, without contradiction, internal combustion cars are characterized by low efficiency at the beginning of the route, which stabilizes at a decent level after driving a few kilometres. (The digestibility of combustion cars increases with the travelled distance). Both types of cars have a reduced performance and reliability in low temperatures.

Based on the above arguments, it can be concluded that electric cars are more efficient at short distances. Certainly, technical progress and the development of renewable energy systems in Poland may change the efficiency of electric vehicles and reduce the carbon footprint of vehicles.

However, the carbon footprint of a product is influenced by its entire life cycle, from the production process, through operation and service to disposal.

Electric drives are more flexible, maintaining good efficiency of motors over a wide range of speeds and loads. This allows the size of the gearboxes to be minimized or eliminated. The electric motor does not require such complex lubrication systems. Electric cars use much less lubricants (including oils, which are quite a significant environmental problem).

In electric cars, it is much easier to implement controlled engine braking, so the wear of braking means and tires during braking is lower. Tire and brake pad dust are artificial 
allergens introduced into our environment to which all road users and their surroundings are exposed. As a result, an apparently healthy and ecological means of transport, such as a bicycle, traveling along busy roads, may cause health complications in the long run.

These arguments strongly support the use of electric vehicles.

But it is the purchase price that determines the use of electric vehicles, operation and the added value for the user in the form of privileges for the owners and users as well as the adaptation of the vehicle to the specific needs of the user or owner.

When analysing the criteria for making a purchase decision and their weights presented in Figure 1, it can be seen that the price of a vehicle is the most important criterion for its purchase, and only then are the operating costs taken into account. For most of the potential so-called mass users, ecological issues are of little importance, and owning an electric vehicle is not associated with prestige. It is true that some of them expect privileges that are only influenced by the state and local authorities.

Other expectations are individual features that adapt the vehicle to the user's needs. Many users note the service life, scalable functionality and susceptibility to modernization. A significant proportion of users use the vehicles locally, covering a few kilometres, often along the same route. It turns out that many users get used to their vehicles and are reluctant to change them to new ones, or change to newer ones of the same brand and model.
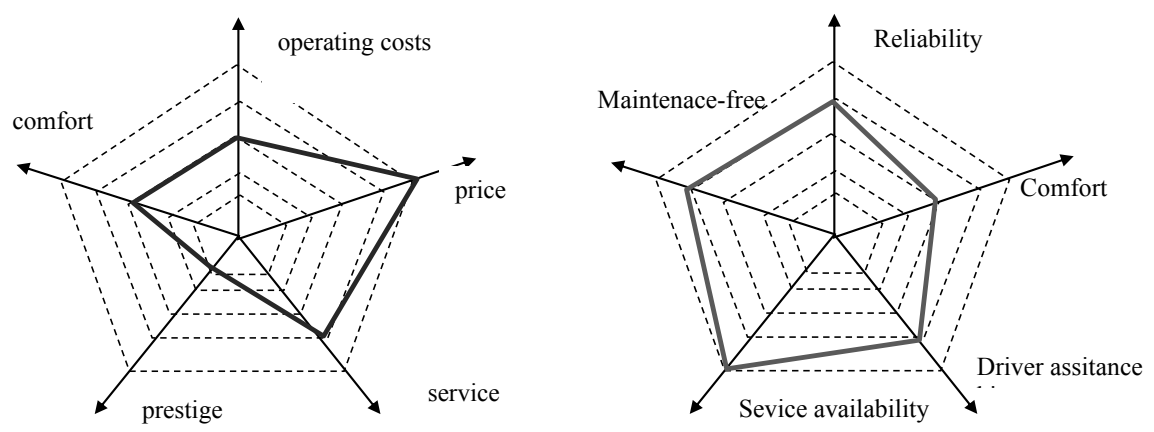

Fig.1 Model of the needs of potential users of electric vehicles. POLEVS own research for the AVANGARD project

Such behavior of potential customers and the relatively simple design of vehicles are conducive to making decisions about the production of cars by local companies that have close contact with the customer and supervise its operation. It is a model from the beginning of the 20th century.

The dedicated production model differs from the OEM production and servicing model, which are focused on the production of standardized solutions in large quantities, and any additional equipment is additionally payable. The user still pays for functions that he does not use. In addition, many companies earn significant revenues from servicing redundant vehicles on the so-called warranty. As a result, many private car users in Poland are eager to buy used, often originating vehicles from Western Europe, where they are resold due to failure to meet the expected ecological standards or being accident cars. However, vehicles of well-known brands are selected due to their prevalence and the number of spare parts. Authorities in Poland, they are not able to stop this process, as it has an economic basis. 


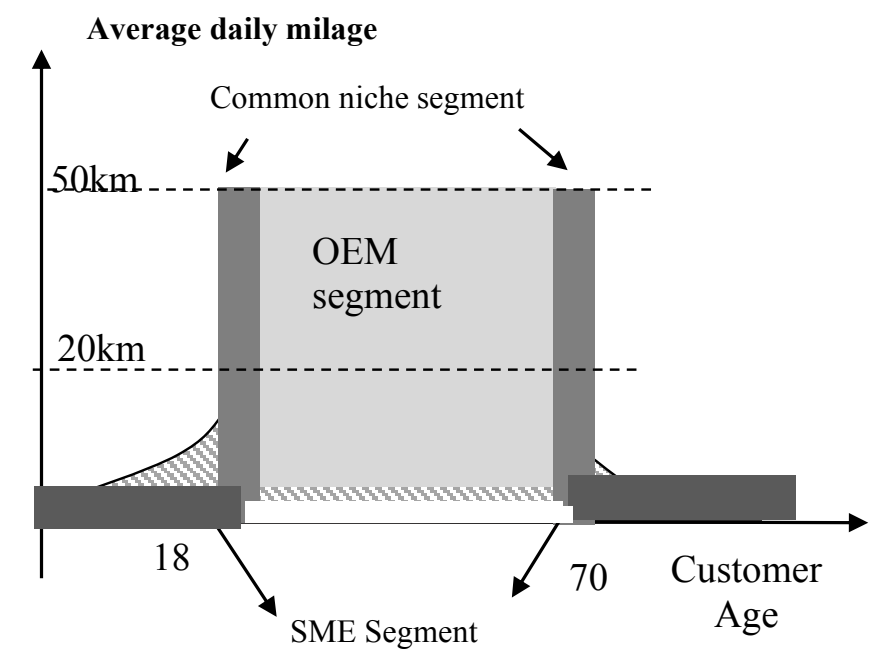

Fig.2 Market sharing between SME and OEM. Polevs analysis results for the AVANGARD project

Local production and servicing optimized to the needs and capabilities of potential users can be a competitive and environmentally friendly solution. Currently, customers expect modern and safe solutions that local production companies cannot afford.

For this reason, the concept of expanding the network of SMEs that will share knowledge was created

and experience in order to provide and maintain high-quality vehicles

and functionality. Preparation and testing of the possibility of developing such a concept is carried out by the consortium of the AVANGARD project, co-financed by the European Commission.

\section{Assumptions of the SME project}

Contemporary requirements for safety and comfort, together with the requirements of ecological production, exceed the capabilities of individual companies, even car OEMs, which jointly develop the essential parts of cars, such as floor plates, engines, body parts, brake systems, etc.

The corporations try to meet the needs of model users, leaving a significant part of the market unsupported. This group of users buys cheap, used cars, being satisfied with their functionality or adapting to their specific requirements.

Following the example of the cooperation of concerns, members of the AVANGARD consortium developed a concept for the production of electric vehicles using modern technologies, manufacturing that allows for low-energy and waste-free production based on the industry concept 4.5 . Close contact with the customer, production with the use of new IT technologies with waste management and, moreover, with the supervision of the product life, aimed at improving manufacturing based on a large scale of experience (many dispersed users).

Developed as part of the project:

- functional and technical assumptions for modular solutions of electric vehicles such as bicycles, scooters and cars, equipped with driver assistance systems: 
- structures based on the use of readily available and recyclable materials

- production method based on additive technologies - waste-free.

- The system of network control of production and testing with the use of the information exchange and registration system of producers' networks.

- System of network supervision over the operation of vehicles.

- A business model for SMEs that undertakes the production of advanced products in the proposed technology - wide application, with a minimal risk of failure, while maintaining high resistance to economic fluctuations.

- Openness of the network of producers connected to the IT network of the vehicle production management system in order to monitor the quality and course of operation in order to gain knowledge.

This will allow for the joint development of modular solutions that will be tailored exactly to the user's needs, the costs of logistics of vehicle repairs will be minimized, as most of the parts can be produced locally in accordance with the documentation available on the web.

The project will result in, inter alia, demonstrators of micro-factories producing vehicles in accordance with the production and service documentation developed and managed in the network.

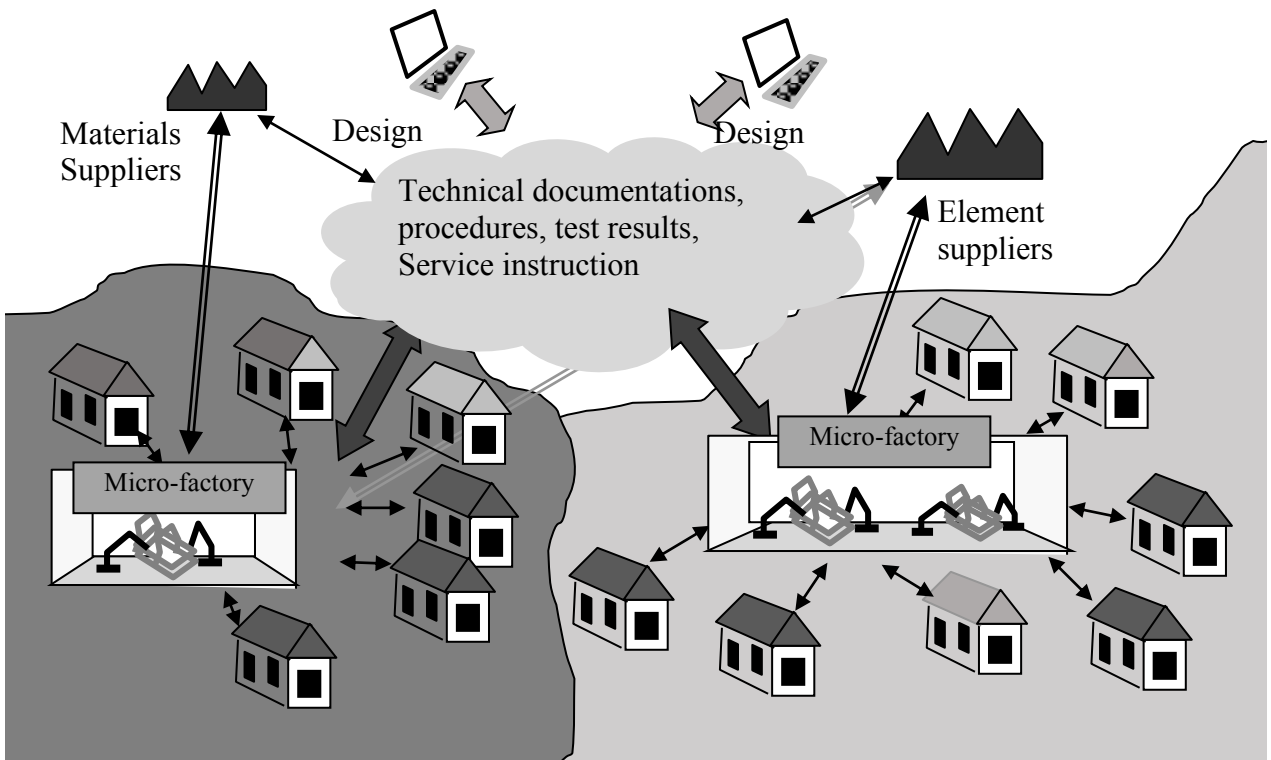

Fig.3. Diagram of the small electric vehicle production network in the AVANGARD network.

\section{Photonic and ultrasonic technologies in small-lot production of vehicles}

Local, small-lot production close to the customer, who is not always familiar with communication via the Internet, requires an innovative approach to the production process. The first step is to design the vehicle together with the use of vehicle visualization and a possible ergonomic simulator of the prepared solution. This requires a dedicated ICT system with dedicated software. Simulators are developed to assess the user's ability and the possibility of adapting the structure to its capabilities. This assessment can be done with the help of on-line experts.

The produced vehicle must meet the quality criteria. With the assumed tubular structure using certified materials, the cutting and welding process must be subject to constant control. For 
this reason, it is based on the use of on-line programmed robots and employee support network, which suggests the sequence of activities and the method of checking. The use of robots ensures repeatability of the product and quality, and computer supervision ensures compliance with the manufacturing procedure.

One of the basic technologies used in production is sheet bending, welding and 3D printing in metal and plastics. The use of tubular welded structures gives great opportunities to modify and repair the structure. Printed elements make it possible to avoid the expensive production preparation process dedicated to large-scale production and transport of elements, as well as the storage of rarely replaced elements. In addition to the laser welding and metal printing system, incremental methods based on supersonic firing of materials are being investigated. All methods are low-waste and the waste can be reused.

In the production process, the costs of producing elements and the impact of their production on the environment are analyzed. The production of energy-intensive components will be scheduled for low energy hours or hours of excess energy production from renewable sources.

\section{Expected benefits}

The expected benefits of the project include accelerating local environmentally friendly transport, facilitating life in smaller communities without public transport, developing local entrepreneurship and stimulating interregional exchange with local specialization. [10]

Satisfying the needs of the market so far overlooked by OEM (concerns and large car companies).

Implementation of the project in a wide international consortium initiates a network of international cooperation of companies and institutions of various types.

The modularity of the structure will allow the use of the produced vehicles as a platform for small construction, municipal and agricultural machines.

In order to test the resilience of the networked vehicle production system to economic changes and crisis, modeling of the market change process was performed using elements of games of chance. The method consisted in developing a product and market development model based on the forecasts contained in the Sustainable Development Strategy. The model of companies participating in the production network included equipment and qualifications of employees, access to documentation and a network of sub-suppliers. The production system in the form of a flow graph was randomly disrupted by breaking branches of cooperation and supply.

It turns out that the proposed solution is very resistant to disrupting the supply chain, as many components can be produced locally. The economic disturbance, with the assumed equipment of micro-factories, allows for quick switching of production to other products or services.

\section{Conclusions}

According to the sustainable development strategy assuming equal opportunities for social development and the development of electromobility, the AVANGARD project is a project dedicated to the Polish economy. Poland, as a producer of car parts, with a large number of SMEs, can quickly build a network of local producers satisfying the individual needs of customers in the field of individual transport. This, in turn, may increase economic activity and entrepreneurship in less developed regions. 
The extension of life and the aging of the society brings about new needs in the field of individual transport, which, among other things, are analyzed and satisfied within the project, by introducing additional driver support systems.

The development of vehicles in accordance with the concept of the AVANGARD project will affect the development of the structure of renewable energy sources, especially those using solar panels, energy management systems with its accumulation in home charging stations.

The creation of a network of electric vehicle manufacturers may be a solution to the problem of production, operation and servicing of electric vehicles, which, according to the consumer model, are missing on the Polish market.

The project will have a stimulating effect on the modification of the road infrastructure communicating with driver support systems built into the vehicle. One of the expected functionalities is supporting drivers by artificial intelligence systems, even in cheap models. The vehicle becomes the user's life assistant and interface with other LA systems, especially for elderly and minors.

The AVANGARD project is financed by EC Horizon 2020, contract 869986

\section{References}

1. G. Kornaros, O. Tomoutzoglou, D. Mbakoyiannis, N. Karadimitriou, M. Coppola, E. Montanari, I. Deligiannis, G. Gherardi, JSA , 109, pp. 1017-1026, (2020)

2. G. Kornaros, D. Bakoyiannis, O. Tomoutzoglou, M. Coppola and G. Gherardi, TrustNet: Ensuring Normal-world and Trusted-world CAN-bus Networking, in Proceedings of the IEEE International Conference on Communications, Control, and Computing Technologies for Smart Grids 2019, pp. 1-6, Beijing, China, (2019)

3. D. Mbakoyiannis, O. Tomoutzoglou, G Kornaros, Secure Over-the-air Firmware Updating for Automotive Electronic Control Units, in Proceedings of the 34th ACM/SIGAPP Symposium on Applied Computing (SAC '19), pp. 174-181, Limassol, Cyprus, (2019)

4. G Kornaros, O Tomoutzoglou, M Coppola, IEEE Micro, 38, pp. 63-74, (2018)

5. M. Massaro, S. Secinaro, F. Dal Mas, V. Brescia, D. Calandra, Industry 4.0 and circular economy: An exploratory analysis of academic and practitioners' perspectives (2020)

6. S. Secinaro, V. Brescia , D. Calandra, P. Biancone. Journal of Cleaner Production 264, 4, (2020)

7. S. Tsiakmakis, G. Fontaras, J. Dornoff, V. Valverde, D. Komnos, B. Ciuffo, Z. Samaras,. Energy, 169 pp. 1153-1165, (2019) 